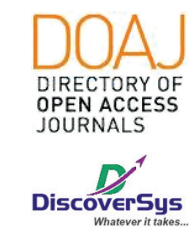

Published by DiscoverSys

\section{The level of knowledge and attitude towards dengue fever among medical students of Udayana University, Bali, Indonesia in 2018}

\author{
Agilan Sethupathy, ${ }^{1{ }^{*}}$ I Made Sudarmaja, ${ }^{2}$ Luh Ariwati ${ }^{2}$
}

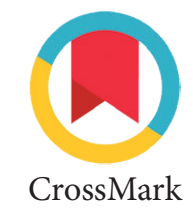
.

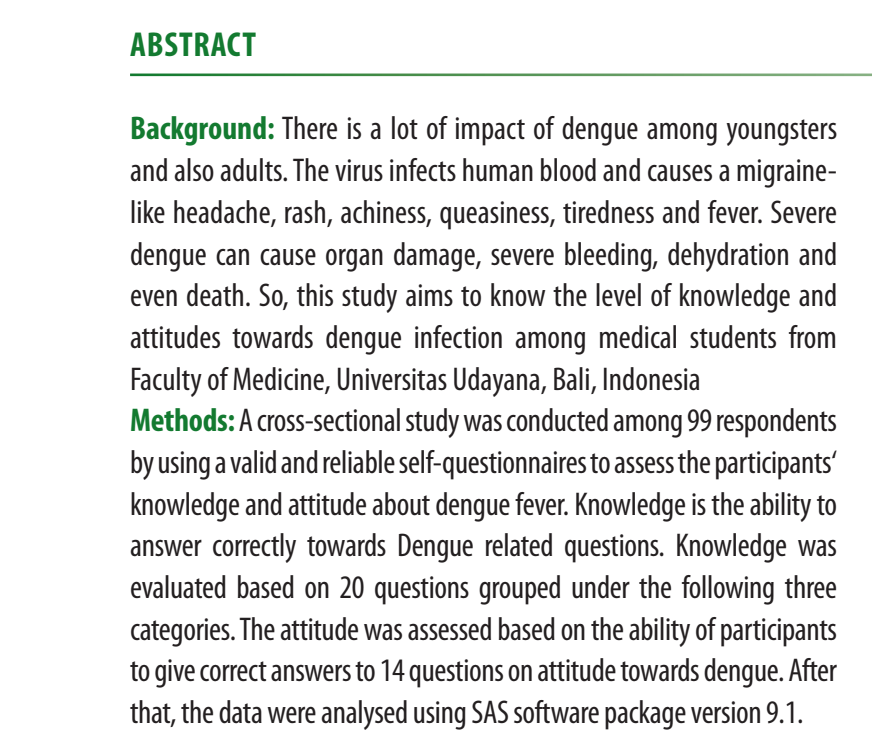

Results: There was $43 \%$ were men and $56 \%$ of women enrolled in this study. Most of them are aged 18 years old $(69.7 \%)$, followed by 19 years old (23.2\%), and 17 years old (6.1\%). The average age was $18.15+0.5$ years old. All of the participants $(100 \%)$ answered that they would go to the doctor they get the dengue infection. Around $94,9 \%$ of them stated that they would drink a lot of water if they get dengue fever, and $89,9 \%$ of them said they would get a lot of rest. The vast majority of participants use insecticide (86,9\%), curtains $(84,8 \%)$, mosquitoes net $(81,8 \%)$, cover their water storage $(98,0 \%)$ and try to not hoard stuff in their home (90,9\%).

Conclusion: The recent findings suggest that most students know the symptoms, transmission, and how to manage dengue fever. The attitudes of participants toward dengue infection have been assessed, and all answered that they would go to the doctor if they get the dengue infection

Keywords: dengue, knowledge, university student

Cite This Article: Sethupathy, A., Sudarmaja, I.M., Ariwati, L. 2019. The level of knowledge and attitude towards dengue fever among medical students of Udayana University, Bali, Indonesia in 2018. Intisari Sains Medis 10(3): 664-670. D0I: 10.15562/ism.v10i3.479

'Undergraduate Medical Student, Faculty of Medicine, Universitas Udayana, Bali, Indonesia ${ }^{2}$ Department of Parasitology, Faculty of Medicine, Universitas Udayana, Bali, Indonesia

${ }^{*}$ Correspondence to: Agilan Sethupathy; Undergraduate Medical Student, Faculty of Medicine, Universitas Udayana, Bali, Indonesia;

gsppittan@gmail.com

Received: 2019-04-06 Accepted: 2019-10-11 Published: 2019-12-01

\section{INTRODUCTION}

Since the beginning of the 21st century, dengue fever (DF) has been the most important vector-borne viral disease in humans, occurring mainly in tropical and sub-tropical countries where over 2.5 billion people are at risk of infection. With an estimated 50-100 million dengue infections worldwide, the disease is currently endemic in more than 125 countries in Africa, the Americas, the Eastern Mediterranean, South-east Asia, and the Western Pacific. ${ }^{1}$

Dengue Hemorrhagic fever causes $40 \%$ of world population to be at risk. Indonesia is the second most endemic country in Southeast Asia in morbidity and mortality rate, after Thailand. This disease can be found in almost every region and any time of the year, with a higher incidence during rainy season, which is generally October to April (the highest incidence usually is during February and March), because it gives a better habitat for the vector, the mosquito, to breed. Dengue is quite common in tropical regions such as Bali heightened during the rainy season that runs from October to April. ${ }^{2}$

Preventing or reducing dengue virus transmission depends largely on controlling the mosquito vectors.
Although the community-wide effort is the key to eradicate dengue, commitment and participation at the individual level such as emptying the flower pot or empty cans and practice of regular removing of water collecting containers and rubbish from their homes, play equally critical role. The Health Belief Model (HBM) is one of the most widely used social cognition models to predict health behaviours. The HBM posits that individual's health behaviour is determined by four main elements: i) consideration of the likelihood (susceptibility); ii) consideration of the seriousness (severity) of illness; iii) perceived benefits of taking health action; iv) perceived barriers to taking health action. ${ }^{3}$

Dengue fever affects the body by causing a high fever and flu-like symptoms in the primary stage. The virus infects human blood and causes a migraine-like headache, rash, achiness, queasiness, tiredness and fever. It can affect the blood, causing mild bleeding of the gums, and may bruise easily. A severe form of the illness that can cause organ damage, severe bleeding, dehydration and even death. $^{2}$ 
Knowledge about dengue and its association with preventive behaviours have not been adequately elucidated. Findings have shown that increased understanding of dengue virus transmission was positively attributed to better dengue prevention practices. The importance of knowing $\mathrm{DF}$ is to make a prevention step before become severe and also be precaution on the cause of DF together avoid it. ${ }^{2}$ Regarding this statement, medical students should have sufficient education about Dengue in general. They should be the guiders for other youths who are out there to prevent and to create awareness about dengue and its preventive methods. Therefore, a survey was conducted among medical students from The Medical Faculty at Universitas Udayana to know their level of knowledge and attitude towards Dengue.

\section{METHODS}

This research is based on a descriptive cross-sectional study where the subjects in the study were medical students at Udayana University. The sample size is based on the number of medical students who volunteered to take part in the survey. The questionnaires were distributed among semester I medical students. The estimated population was calculated to be 100 .

The study was conducted using self-administered questionnaires. The questionnaire was divided into 2 parts. Part A was on Basic details of the participant, and Part B is the knowledge and attitude test towards DF. Knowledge is the ability to answer correctly towards Dengue related questions. Knowledge was assessed based on 20 questions grouped under the following three categories: i) Knowledge of the symptoms of dengue; ii) Knowledge of dengue transmission; iii) Knowledge of dengue management. The attitude was assessed based on the ability of participants to give correct answers to 14 questions on attitude towards dengue. After that, the data were analysed using SAS software package version 9.1.

\section{RESULTS}

A total of 99 respondents voluntarily joined the study. They consist of $43 \%$ men and 56\% women. Most of them aged 18 years old (69.7\%), followed by 19 years old $(23.2 \%)$, and 17 years old $(6.1 \%)$. There was 1 participant who was aged 17 years old. The age average was $18.15+0.5$ years old. All the participants filled the questionnaires and understood all questions.

Overall knowledge of the participant was good, with more than half of them answered the right answer for the questions (Table 1). Nevertheless, in some questions, participants got confused and chose either the wrong answer or admitted they did not know about that statement. For instance, in the question -Is retro-orbital pain one of the dengue fever's symptoms?" around 53.5\% of them answer they do not know about that, and only $32.3 \%$ answered it correctly. In the question - Does dengue can spread with transfusion?" there were $33.3 \%$ of participant who answered wrongly by choosing -yes. The other two questions which confuse the participants were "When will dengue vectors bite their victims?" where majority of participant answered it wrongly and "Is aspirin consumption necessary for dengue infection?. Where there was $32.3 \%$ participant who answered incorrectly (Table 1).

All the participants answered that they would go to the doctor they get the dengue infection. Around $94.9 \%$ of them stated that they would drink a lot of water if they get dengue fever, and $89.9 \%$ of them said they would get a lot of rest. These answers were appropriate acts as a self-handle of dengue fever (Table 2). Majority of them shows good attitudes to prevent dengue infection by more than half of them chose the correct action to prevent dengue infection. The vast majority of participants use insecticide (86.9\%), curtains (84.8\%), mosquitoes net $(81.8 \%)$, cover their water storage $(98.0 \%)$ and try to not hoard stuff in their home (90.9\%) in order to avoid mosquitoes, contact that can higher the risk of getting dengue infection (Table 2).

\section{DISCUSSION}

In this study, the author found that overall knowledge and attitudes of medical students towards dengue fever were good. This result similar to a study by Nasir in Malaysia where they found most of the respondents had good knowledge (63.2\%) and good attitudes (79.9\%). ${ }^{4}$ Another similar study by Bota found that $94.6 \%$ of participants reported that they had heard about dengue, and $58.6 \%$ of participants reported "Aedes mosquito" as a vector of dengue virus. The Aedes mosquito is - a small dark mosquito having white stripes on its legl was reported by $54.8 \%$ students. The Aedes mosquito breeds in "Stagnant clean water" was reported by $47.6 \%$ students and usually bit at "Dusk" by $44.7 \%$ and at "Dawn" by $51 \%$. Regarding symptoms of dengue fever, "Prolonged high fever" was reported by $52.6 \%$, "Muscular pain" by $39.6 \%$ (p-value 0.009), "Bleeding" by $41.3 \%$ (p-value $=0.001$ ) and "Headache, nausea and vomiting" by $44.7 \%$ $(\mathrm{p}$-value $=0.001) .{ }^{5}$

Research on first-year medical students by Mirza found that 33(25\%) respondents knew that there are four types of Dengue Fever, $44 \%$ correctly 
Table 1 The answers of participants regarding knowledge on dengue fever

\begin{tabular}{|c|c|c|c|}
\hline No. & Question & Answer & $\begin{array}{c}\text { Frequency } \\
(\mathbf{n}, \%)\end{array}$ \\
\hline \multirow[t]{3}{*}{1} & Is fever one of the dengue fever's symptoms? & Yes $^{*}$ & $95(96.0)$ \\
\hline & & No & $2(2.0)$ \\
\hline & & Don't Know & $2(2.0)$ \\
\hline \multirow[t]{3}{*}{2} & Is headache one of the dengue fever's symptoms? & Yes $^{*}$ & $79(79.8)$ \\
\hline & & No & $5(5.1)$ \\
\hline & & Don't Know & $15(15.2)$ \\
\hline \multirow[t]{3}{*}{3} & Is arthralgia one of the dengue fever's symptoms? & Yes $^{*}$ & $53(53.5)$ \\
\hline & & No & $17(17.2)$ \\
\hline & & Don't Know & $29(29.3)$ \\
\hline \multirow[t]{3}{*}{4} & Is myalgia one of the dengue fever's symptoms? & Yes $^{*}$ & $59(59.6)$ \\
\hline & & No & $9(9.1)$ \\
\hline & & Don't Know & $31(31.3)$ \\
\hline \multirow[t]{3}{*}{5} & Is retro-orbital pain one of the dengue fever's symptoms? & Yes $^{*}$ & $32(32.3)$ \\
\hline & & No & $14(14.1)$ \\
\hline & & Don't Know & $53(53.5)$ \\
\hline \multirow[t]{3}{*}{6} & Does fly spread dengue virus to a human? & Yes $^{*}$ & $5(5.1)$ \\
\hline & & No & $86(86.9)$ \\
\hline & & Don't Know & $8(8.1)$ \\
\hline \multirow[t]{3}{*}{7} & Do all types of mosquitoes spread dengue virus? & Yes $^{*}$ & $4(4.0)$ \\
\hline & & No & $94(95.0)$ \\
\hline & & Don't Know & $1(1.0)$ \\
\hline \multirow[t]{3}{*}{8} & Does aedes mosquito spread dengue virus? & Yes $^{*}$ & $81(81.8)$ \\
\hline & & No & $18(18.2)$ \\
\hline & & Don't Know & $0(0.0)$ \\
\hline \multirow[t]{3}{*}{9} & Can dengue virus spread by transfusion? & Yes $^{*}$ & $33(33.3)$ \\
\hline & & No & $43(43.4)$ \\
\hline & & Don't Know & $23(23.2)$ \\
\hline \multirow[t]{3}{*}{10} & Can dengue virus spread from human to human? & Yes $^{*}$ & $14(14.1)$ \\
\hline & & No & $77(77.8)$ \\
\hline & & Don't Know & $8(8.1)$ \\
\hline \multirow[t]{3}{*}{11} & Can dengue virus spread by needle injection? & Yes $^{*}$ & $22(22.2)$ \\
\hline & & No & $53(53.5)$ \\
\hline & & Don't Know & $24(24.2)$ \\
\hline \multirow[t]{3}{*}{12} & When will dengue vectors bite their victims? & Yes $^{*}$ & $39(39.4)$ \\
\hline & & No & $38(38.4)$ \\
\hline & & Don't Know & $22(22.2)$ \\
\hline \multirow[t]{3}{*}{13} & Do some window sheets and mosquito net prevent the spread? & Yes $^{*}$ & $86(86.9)$ \\
\hline & & No & $3(3.0)$ \\
\hline & & Don't Know & $10(10.1)$ \\
\hline \multirow[t]{3}{*}{14} & Can closed water storage container decrease mosquito reproduction? & Yes* $^{*}$ & $95(96.0)$ \\
\hline & & No & $2(2.0)$ \\
\hline & & Don't Know & $2(2.0)$ \\
\hline
\end{tabular}


Table 1 Continued

\begin{tabular}{|c|c|c|c|}
\hline No. & Question & Answer & $\begin{array}{c}\text { Frequency } \\
(\mathbf{n}, \%)\end{array}$ \\
\hline \multirow[t]{3}{*}{15} & Can mosquito repellent tools decrease their reproduction? & Yes $^{*}$ & $76(76.8)$ \\
\hline & & No & $18(18.2)$ \\
\hline & & Don't Know & $5(5.1)$ \\
\hline \multirow[t]{3}{*}{16} & Can tree cutting decrease mosquito reproduction? & Yes $^{*}$ & $71(71.7)$ \\
\hline & & No & $12(12.1)$ \\
\hline & & Don't Know & $16(16.2)$ \\
\hline \multirow[t]{3}{*}{17} & Is aspirin consumption necessary for dengue infection? & Yes $^{*}$ & $32(32.3)$ \\
\hline & & No & $36(36.4)$ \\
\hline & & Don't Know & $31(31.3)$ \\
\hline \multirow[t]{3}{*}{18} & Can dengue infection be treated? & Yes $^{*}$ & $91(91.9)$ \\
\hline & & No & $2(2.0)$ \\
\hline & & Don't Know & $6(6.1)$ \\
\hline \multirow[t]{5}{*}{19} & Do you think dengue fever is a severe disease? & Very Agree & $30(30.3)$ \\
\hline & & Agree & $57(57.6)$ \\
\hline & & Less Agree & $11(11.1)$ \\
\hline & & Not Agree & $0(0.0)$ \\
\hline & & Not Sure & $1(1.0)$ \\
\hline \multirow[t]{5}{*}{20} & Do you have a risk to get dengue infection? & Very Agree & $35(35.4)$ \\
\hline & & Agree & $37(37.4)$ \\
\hline & & Less Agree & $21(21.2)$ \\
\hline & & Not Agree & $2(2.0)$ \\
\hline & & Not Sure & $4(4.0)$ \\
\hline \multirow[t]{5}{*}{21} & Do you think you can avoid dengue infection? & Very Agree & $40(40.4)$ \\
\hline & & Agree & $38(38.4)$ \\
\hline & & Less Agree & $9(9.1)$ \\
\hline & & Not Agree & $11(11.1)$ \\
\hline & & Not Sure & $1(1.0)$ \\
\hline
\end{tabular}

Table 2 The answers of respondents regarding attitude on dengue fever

\begin{tabular}{llcc}
\hline No. & Question & Answer & Frequency (n,\%) \\
\hline $1 \quad$ Will you get a lot of rest if you get dengue infection? & Yes & $89(89,9)$ \\
& & No & $4(4,0)$ \\
& & Don't Know & $6(6,1)$ \\
2 & Will you drink a lot of water if you get dengue infection? & Yes & $94(94,9)$ \\
& & No & $0(0.0)$ \\
3 & Will you go to the doctor if you get dengue infection? & Don't Know & $5(5.1)$ \\
& & Yes & $99(100.0)$ \\
& & No & $0(0.0)$ \\
4 & Do you use an insecticide to reduce mosquitoes? & Don't Know & $0(0.0)$ \\
& & Yes & $86(86.9)$ \\
5 & Do you use professional midges to reduce mosquitoes? & No & $13(13.1)$ \\
& & Yes & $76(76.8)$ \\
\hline
\end{tabular}


Table 2 Continued

\begin{tabular}{|c|c|c|c|}
\hline No. & Question & Answer & Frequency $(\mathbf{n}, \%)$ \\
\hline \multirow[t]{2}{*}{6} & Do you use a curtain to reduce mosquitoes? & Yes & $84(84.8)$ \\
\hline & & No & $15(15.2)$ \\
\hline \multirow[t]{2}{*}{7} & Do you use a fan to reduce mosquitoes? & Yes & $52(52,5)$ \\
\hline & & No & $47(47.5)$ \\
\hline \multirow[t]{2}{*}{8} & Do you use a mosquito net to reduce mosquitoes? & Yes & $81(81.8)$ \\
\hline & & No & $18(18.2)$ \\
\hline \multirow[t]{2}{*}{9} & Do you cut the bushes in your garden to reduce mosquito? & Yes & $51(51.5)$ \\
\hline & & No & $48(48.5)$ \\
\hline \multirow[t]{2}{*}{10} & Do you use fish to reduce mosquitoes? & Yes & $68(68.7)$ \\
\hline & & No & $31(31.3)$ \\
\hline \multirow[t]{2}{*}{11} & Do you use burned mosquito's repellent? & Yes & $75(75.8)$ \\
\hline & & No & $24(24.2)$ \\
\hline \multirow[t]{2}{*}{12} & Do you not hoarding to reduce mosquitoes? & Yes & $90(90,9)$ \\
\hline & & No & $9(9.1)$ \\
\hline \multirow[t]{2}{*}{13} & Do you use a cover in your water reservoir storage? & Yes & $97(98,0)$ \\
\hline & & No & $2(2.0)$ \\
\hline \multirow[t]{4}{*}{14} & How often you clean your water reservoir and trench? & Always & $57(57.6)$ \\
\hline & & As often as possible & $32(32.3)$ \\
\hline & & Sometimes & $9(9.1)$ \\
\hline & & Never & $1(1.0)$ \\
\hline
\end{tabular}

named the causative agent as flavivirus and $65 \%$ of students were aware that the incubation period of Dengue Fever is 4-7 days. Among the respondents, $87 \%$ knew that the vector of this disease is female mosquitoes, though only $39 \%$ of students rightly named the species like Aedes aegypti. Around 90\% students correctly answered high fever, severe headache, pain behind eyes, muscle and joint pains and rash as a symptom of dengue infection. ${ }^{6}$

Regarding the attitudes, a study by Amanah in Malaysia shows that the vast majority of medical students had good attitudes regarding dengue infection. They agreed to seek professional treatment if they get the infection and also agreed with the necessity of elimination larvae breeding with some efforts such as fogging, covering water storage, using water repellent and also applying mosquitos net and curtains (95.2\%-99.6\%). ${ }^{7}$

In the aspect of knowledge, it is noteworthy to see that there were still a mistake and lack of knowledge about retro-orbital pain as one of the dengue fever symptoms. The study by Cherng stated that ocular pain is described in 8 out of 29 papers as presenting dengue fever symptoms. Pain mostly located in retrobulbar and sometimes diffused. The patients with retrobulbar pain consisted of those who presented with subconjunctival haemorrhage and retinopathy sparing the macula, stellar neuroretinitis, and retinal haemorrhages. ${ }^{8}$ The causes of haemorrhage could be thrombocytopenia with coagulation defects, capillary fragility, consumptive coagulopathy, and platelet dysfunction. Generally, there is complete resolution of ocular changes in dengue fever. ${ }^{9}$

The other issues that still become a pitfall in dengue fever knowledge were about its vector and how it spreads. Dengue is one of the arboviruses which mean it needs an insect for some phase of their cycles to eventually infect the human host. Aedes aegypti is a necessary vector for dengue virus. Besides dengue virus, it also plays a role in spreading the virus that is contributed to yellow fever, chikungunya and Zika virus. A study that analyses the characteristics of Aedes aegypti found that most of the mosquitos more often can be found indoors compare to outdoor $(p<0,001)$. The peak of mosquito existences is on the evening and night which is around 4:30 pm -7:30 pm for outdoor mosquitos, whereas it will be on $6: 30 \mathrm{pm}-7: 30 \mathrm{pm}$ for indoor mosquitos. The highest prevalence of Aedes aegypti will be on March and April. ${ }^{10}$

In a recent discussion, some of the publications stated their concern about the possibility of dengue virus could be transferred by blood transfusion. Transfusion transmitted-DENV (TT-DENV) has been reported in Singapore, Hong Kong, Puerto Rico, and Brazil. However, no other countries reported the incidence nor have taken a 
further study to analyse whether the infection is caused purely by the transfusion or not. A survey conducted by Rooks showed that none of the blood samples collected during local dengue outbreaks were positive for DENV RNA despite a subset being collected from - higher-risk\| areas. ${ }^{11}$ It is known that dengue as an arbovirus need its vector, which in this case is Aedes aegypti to incubate and replicate for about a couple days until they can bite and infect the person. ${ }^{11,12}$ Female mosquitoes get infected by biting infected humans during their viremic phase; after 7 to $14 \mathrm{~d}$ of incubation, the mosquito is able to transmit the virus via blood-feeding. Besides mosquito biting, DENV may be accidentally acquired after vertical transmission, especially in near-term pregnant women through the placenta. Although this fact is still in the debate, we still have to put a precaution in the blood with high load of dengue viral (from $10^{4}$ to $10^{8}$ copies $/ \mathrm{mL}$ ) and variant DEN V with higher risk of transmission through blood. ${ }^{13}$

Some students are still confused whether they should use Aspirin or not manage dengue fever. A lot of treatment and management guidelines for dengue fever do not include the use of Nonsteroidal Anti Inflammatory Drugs (NSAIDs) and focus on fluid therapy for dengue fever management. On the contrary, they even stated that the use of NSAIDs such as aspirin is forbidden in the case of dengue infection. The reason is that NSAIDs can alter platelets aggregation, therefore higher the risk of bleeding in dengue fever and dengue hemorrhagic fever. Moreover, the reason for the students not to know much about aspirin is because Aspirin uses to be banned for those under 16-year-olds. The UK Medicines Control Agency has recommended that children under 16 should not be given aspirin, because of its links with Reye's syndrome, the rare but potentially fatal disorder found almost exclusively in children and adolescents. ${ }^{14}$

To date, paracetamol is being used as the pain killer. Aspirin, ibuprofen and paracetamol are all effective painkillers. Paracetamol is typically used for mild or moderate pain. It may be better than aspirin for headaches, toothache, sprains, stomach ache, and nerve pain like sciatica, but there is no any side effect. A study conducted by Wijewickrama proved that among 919 dengue fever patients, $36.7 \%$ of NSAIDs user-developed bleeding while only $28 \%$ of non NSAIDs user-developed bleeding $(p<0,005)$. They also found liver enzyme derangement in Dengue patients who consumed NSAIDs with $25 \%$ of them had ALT $>300 \mu / L$ whereas it only happened in $14.8 \%$ non NSAIDs consumers $(\mathrm{p}<0,005) .{ }^{15}$

\section{CONCLUSION}

Based on the findings in this study, we can conclude that a total of 99 respondents voluntarily join the study. Around $70.4 \%$ of students knew the symptoms of dengue fever, $72.3 \%$ understood the transmission of dengue and $71.3 \%$ knew how to manage dengue. The attitudes of participants toward dengue infection have been assessed and all answered that they will go to the doctor they get the dengue infection. Around $94.9 \%$ of them stated that they will drink a lot of water if they get dengue fever, and $89.9 \%$ of them stated they will get a lot of rest. These answers were appropriate acts as a self-handle of dengue fever. Majority of them shows good attitudes to prevent dengue infection by more than half of them choose the correct action to prevent dengue infection. The vast majority of participants use insecticide $(86,9 \%)$, curtains $(84,8 \%)$, mosquitoes net $(81,8 \%)$, cover their water storage $(98,0 \%)$ and try to not hoard stuff in their home $(90,9 \%)$ in order to avoid mosquitoes, contact that can increase the risk of getting dengue infection.

\section{ETHICS CONSIDERATION}

Ethics approval has been obtained from the Ethics Committee, Faculty of Medicine, Universitas Udayana, Bali, Indonesia prior to the study being conducted.

\section{CONFLICT OF INTEREST}

There is no competing interest regarding the manuscript.

\section{FUNDING}

The authors are responsible for the funding of study without the involvement of grant, scholarship, or any other resources of funding.

\section{AUTHOR CONTRIBUTION.}

All of the authors are equally contributed to this study from the conceptual framework until reporting the results of study.

\section{REFERENCES}

1. Bhatt S, Gething PW, Brady OJ, Messina JP, Farlow AW, Moyes CL et.al. The global distribution and burden of dengue. Nature. 2013; 496(7446):504-7.

2. Shepard DS, Undurraga EA, Halasa YA, Stanaway JD. The global economic burden of dengue: a systematic analysis. Lancet Infect Dis. 2016;16(8):935-41.

3. Rahim AR, Ibrahim F, Taib MN. System identification on nonlinear autoregressive models in monitoring dengue infection. Int J Smart Sensing Intelligent Systems. 2010;3(4):783-805 
4. Nasir BM, Fuad MD, Abdelqader MA, Baobaid MF, Elnajeh M, Ghazi HF, et al. Knowledge, attitude and practice of dengue fever and health education programme among students of Alam Shah Science School, Cheras Malaysia. Malaysian Journal of Public Health Medicine. 2015;15 (2):69-74

5. Bota R, Ahmed M, Jamali M, Aziz A. Knowledge, attitude and perception regarding dengue fever among university students of interior Sindh. J Infect Public Health. 2014;7(3):218-23.

6. Mirza H, Raza H, Bashir R. Knowledge, Attitude \& Perception of Dengue among First Year Medical Students. PJMHS. 2013;7(1):258-63

7. Amanah, M., Abdullah, H., Ghafar, N. 2018. Knowledge attitude and practice on dengue among university students. Int J Community Med Public Health. 2018;5(11):4720-724

8. Yip VC, Sanjay S, Koh YT. Ophthalmic complications of dengue Fever: a systematic review. Ophthalmol Ther. 2012;1(1): 2 .

9. Sujatha R, Nousheen S, Nazlin A, Prakash S. Ocular manifestations of dengue fever. International Journal of Medical Science and Public Health. 2015;41(8):690-93.

10. Ndega B, Mutuku F, Ngugi H, Mbakaya O, Aswani, P, Musunzanju P, et al. Characteristics of Aedes egypti adult mosquitoes in rural and urban areas of western and coastal Kenya. Plos One. 2017;12(2):e0189971
11. Rooks K, Seed CR, Fryk JJ, Hyland CA, Harley RJ, Holmberg JA, et al. Mitigating the risk of transfusion transmitted dengue in Australia. J Blood Transfus. 2016;2016:3059848

12. Teo D, Ng L, Lam S. Is dengue a threat to the blood supply? Transfus Med; 2009;19(2):66-77.

13. Pozzetto B, Memmi M, Garraud O. Is transfusion-transmitted dengue fever a potential public health threat? World J Virol. 2015;4(2):113-23.

14. Macdonald S. Aspirin use to be banned in under 16 year olds. BMJ. 2002;325(7371):988

15. Wijewickrama A, Aberyathna G, Gunasena S, Idampitiya D. Effect of non-steroidal anti-inflammatory drugs (NSAIDS) on bleeding and liver in dengue infection. International Journal of Infectious Diseases. 2016;45S;1- 477.

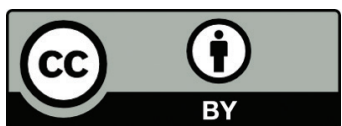

This work is licensed under a Creative Commons Attribution 